\title{
A Participação de Médicos nas Atividades da Agência Europeia de Medicamentos
}

\section{Physician Involvement in the Activities of the European Medicines Agency}

Ivana SILVA $\bowtie 1$

Acta Med Port 2017 Nov;30(11):759-761 - https://doi.org/10.20344/amp.9871

\begin{abstract}
RESUMO
Durante mais de duas décadas de atividade, a Agência Europeia de Medicamentos estabeleceu-se em rede com as agências nacionais do medicamento, congregando - nos seus vários comités científicos e grupos de trabalho - peritos europeus provenientes das mais variadas vertentes da avaliação da qualidade, segurança e eficácia de medicamentos. $O$ trabalho que se realiza no âmbito das atividades da Agência Europeia de Medicamentos e as conclusões a que se chegam a nível Europeu afetam milhões de cidadãos. A Agência Europeia de Medicamentos considera ser de grande importância manter, de forma sustentável e consistente, a participação ativa de médicos de Medicina Geral e Familiar, assim como de outras especialidades médicas, no processo de avaliação e monitorização de medicamentos. O presente artigo aborda de forma resumida como se promove a participação de médicos e profissionais de saúde, em geral, nas atividades da Agência Europeia de Medicamentos.
\end{abstract}

Palavras-chave: Aprovação de Medicamentos; Órgãos Governamentais; Pessoal de Saúde; União Europeia

\section{ABSTRACT}

For more than two decades of activity, the European Medicines Agency has been operating as part of a network with the national medicines agencies in Europe, bringing together - in its various scientific committees and working groups - European experts on a wide range of topics related to quality assurance, safety and efficacy of medicines. The work carried out within the European Medicines Agency activities and the conclusions reached at European level affect millions of citizens. The European Medicines Agency considers that it is of great importance to maintain, in a sustainable and consistent manner, the active participation of general practitioners, as well as other medical specialists, in the process of medicines' evaluation and supervision. This article summarizes how the participation of doctors and health professionals in general is promoted in the European Medicines Agency activities.

Keywords: Drug Approval; European Union; Government Agencies; Health Personnel

A Agência Europeia de Medicamentos (EMA) tem muitos nomes - 24, para ser precisa; tantos, quantas as línguas oficiais da União Europeia (UE). Nos dias que correm, porém, é mais conhecida por 'EMA'. Mas conhecer a EMA é algo relativo e não nos podemos convencer que todos sabem o que é e o que faz.

Durante mais de duas décadas de atividade, a EMA ${ }^{1}$ estabeleceu-se em rede com as agências nacionais do medicamento, congregando nos seus vários comités científicos e grupos de trabalho peritos europeus nas mais variadas vertentes da avaliação da qualidade, segurança e eficácia de medicamentos. São muitos os médicos e farmacêuticos que compõem tais estruturas. $O$ trabalho que aqui se realiza e as conclusões a que se chegam afetam milhões de cidadãos europeus. Contudo, ainda se encontra facilmente por essa Europa fora quem não saiba que o medicamento que está a tomar é o resultado de todo um esforço europeu para assegurar que o possa fazer, e de forma segura e eficaz.

Também não é do conhecimento geral que para esse resultado contribuíram não apenas inúmeros peritos em regulamentação farmacêutica, bioestatística, toxicologia, farmacologia, farmacoepidemiologia, e tantas outras áreas de conhecimento especializado mas, também, e não de somenos importância, clínicos e doentes.

De facto, a EMA tem vindo a desenvolver um trabalho de fundo na sistematização da participação de doentes e profissionais de saúde nas suas diversas áreas de atividade. O intuito é o de permitir que a evidência que suporta a autorização de comercialização de um novo medicamento, ou qualquer alteração nos medicamentos já comercializados, seja colocada no contexto de condições reais da prática clínica e prestação de cuidados de saúde.

Farei aqui uma breve abordagem à forma como se promove a participação de médicos (e profissionais de saúde, em geral) nas atividades da EMA. Tal participação está prevista a vários níveis, de acordo com o programa quadro de interação com profissionais de saúde e as suas organizações representativas. ${ }^{2}$

Os principais objetivos do programa quadro são: i) apoiar um acesso mais alargado a profissionais de saúde independentes e com experiência em qualquer assunto relacionado com medicamentos; ii) contribuir para uma comunicação mais eficiente e direcionada aos profissionais de saúde; e iii) melhorar o entendimento que as organizações de profissionais de saúde têm sobre o papel da Rede Regulamentar Europeia do Medicamento.

Neste espírito, o programa quadro reconhece as organizações de profissionais de saúde, incluindo sociedades de ciências médicas, como canais facilitadores de acesso à comunidade médica e de transmissão de informações e resultados sobre as avaliações de medicamentos efetuadas.

1. European Medicines Agency. Londres. Reino Unido.

$\triangle$ Autor correspondente: Ivana Silva. ivana.silva@ema.europa.eu

Recebido: 20 de outubro de 2017 - Aceite: 06 de novembro de 2017 | Copyright @ Ordem dos Médicos 2017 
Existem essencialmente duas vias para interagir com a EMA. A primeira, como perito individual e a segunda, como representante de uma organização profissional. Há uma terceira via, que pressupõe a nomeação pela Comissão Europeia de representantes no Conselho de Administração da EMA e nos comités científicos onde tal participação está prevista pela legislação farmacêutica [a saber, no Comité Pediátrico (PDCO), no Comité de Terapias Avançadas (CAT) e no Comité de Avaliação do Risco em Farmacovigilância (PRAC)] (Fig. 1). Quando os profissionais de saúde são envolvidos em atividades relacionadas com um medicamento específico, fazem-no na capacidade de perito individual. A EMA solicita às organizações de profissionais de saúde relevantes que identifiquem peritos que possam fornecer o seu contributo, com base na sua experiência clínica individual. Todos os peritos estão sujeitos à avaliação de interesses declarados e a confidencialidade. Por exemplo, o Comité de Medicamentos de uso Humano (CHMP) e o PRAC são apoiados por Grupos Consultivos Científicos (SAGs) e grupos ad hoc de especialistas para fornecer aconselhamento em relação à avaliação de medicamentos específicos. Eles são compostos por especialistas europeus selecionados de acordo com os conhecimentos específicos necessários. Os especialistas são envolvidos nas reuniões destes grupos para apoiar discussões científicas relacionadas com a avaliação de novos pedidos de autorização de mercado e mudanças nas indicações de medicamentos já aprovados. Através de uma rede de organizações europeias de profissionais de saúde, a Agência convida especialistas individuais a participar neste tipo de reuniões para partilhar a sua experiência e prática clínica.

O envolvimento também pode ocorrer na forma de consultas escritas, tais como as realizadas para assegurar que a informação incluída no resumo das características do medicamento seja o mais clara possível (por exemplo, recomendações de posologia ou instruções de uso do medicamento).

Em consonância com o programa quadro da EMA para a interação com profissionais de saúde, também é possível que um comité científico ou grupo de trabalho solicite contribuições de organizações em questões gerais. O objetivo dessas consultas é o de recolher informações adicionais sobre certos aspetos da prática clínica e padrões de cuidados que podem apoiar os comités nas suas discussões, tanto a nível de avaliação de pedidos de autorização como no desenvolvimento de normas orientadoras para investigadores e laboratórios farmacêuticos.

Além disso, o Grupo de Trabalho da EMA com Organizações de Profissionais de Saúde (HCPWP, na sua sigla Inglesa), formalmente estabelecido em junho de 2013, desempenha um papel fundamental na interação da Agência com as organizações de profissionais de saúde. Trata-se de uma plataforma composta por 20 organizações europeias e representantes dos seis comités científicos da EMA para medicamentos de uso humano. Esta plataforma congrega representantes médicos, farmacêuticos e enfermeiros e ajuda a fornecer recomendações à EMA e aos seus comités científicos sobre todos os aspetos relacionados com medicamentos. O grupo reúne três vezes ao ano, sendo algumas das reuniões plenárias organizadas com o grupo homólogo de Doentes e Consumidores (PCWP).

A Agência considera ser de grande importância manter, de forma sustentável e consistente, a participação ativa de médicos de Medicina Geral e Familiar, assim como de outras especialidades médicas, no processo de avaliação e monitorização de medicamentos. A nível europeu tal é conseguido com o apoio das organizações representativas que se encontram listadas na página web da EMA. ${ }^{3}$

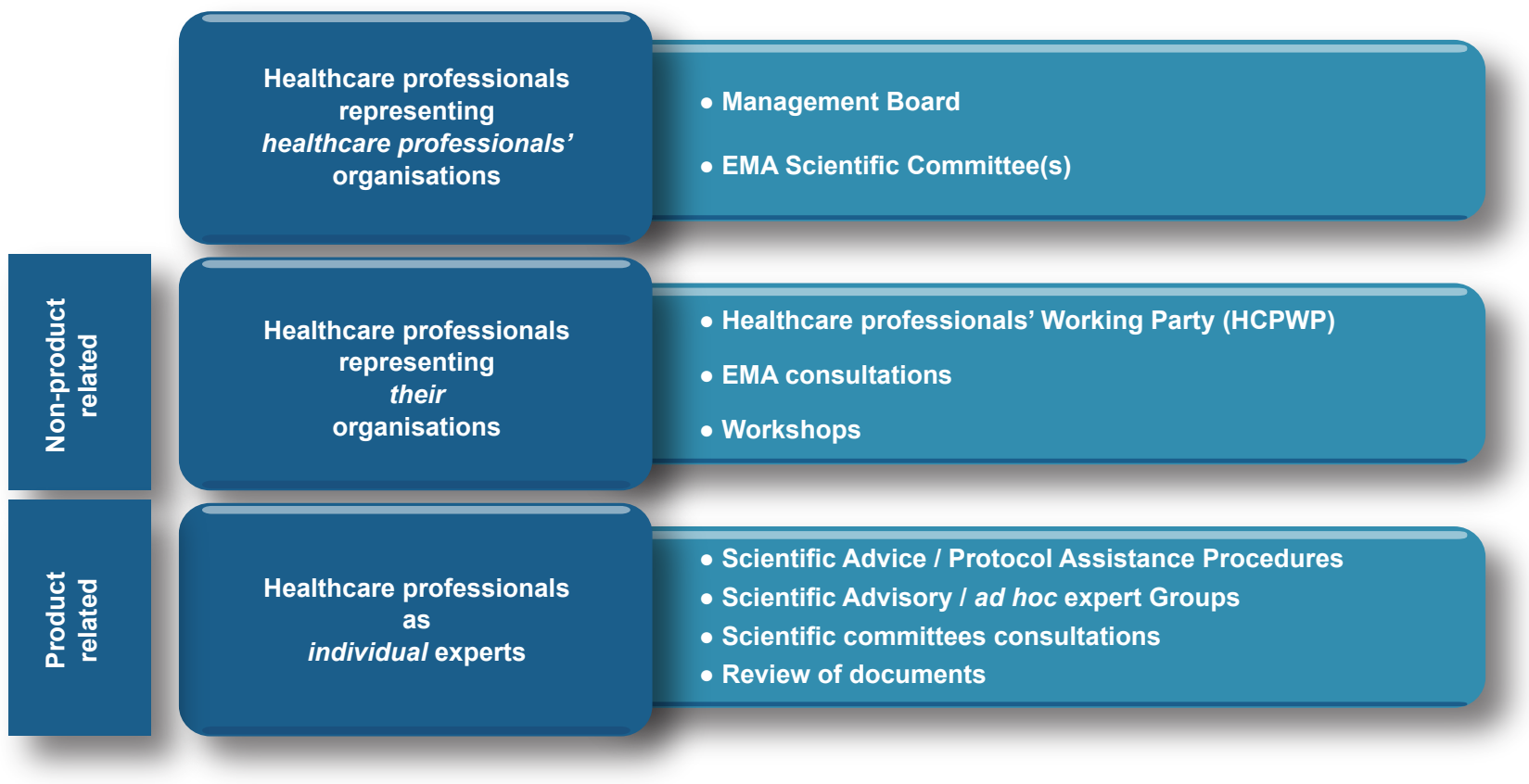

Figura 1 - Âmbito da representação de profissionais de saúde nas actividades da EMA Fonte: Agência Europeia de Medicamentos 
Termino com um convite à navegação da página da EMA - www.ema.europa.eu - onde se podem encontrar alguns materiais audiovisuais que explicam mais detalha-

\section{REFERÊNCIAS}

1. Agência Europeia de Medicamentos. Visão geral das principais responsabilidades da Agência Europeia de Medicamentos. [Consultado 2017 out 30]. Disponível em: http://www.ema. europa.eu/docs/pt_PT/ document_library/Other/2016/08/WC500211862.pdf.

2. Revised framework for interaction between the European Medicines Agency and healthcare professionals and their organizations. damente o trabalho desta Agência e da sua interação com profissionais de saúde e doentes.

[Consultado 2017 out 30]. Disponível em: http://www.ema.europa.eu/ docs/en_GB/document_library/Other/2016/12/WC500218303.pdf

3. Eligible healthcare professionals' organisations. [Consultado 2017 out 30]. Disponivel em: http://www.ema.europa.eu/ema/ index.jsp?curl=pages/partners_and_networks/q_and_a/q_and_a_ detail_000130.jsp\&mid=WC0b01ac05805c0cad. 